\title{
MERLEAU-PONTY, LACAN E PESSOA: $O$ ESFACELAMENTO PULSIONAL DA VISÃO
}

\author{
Maicon Reus Engler* \\ Universidade Federal de Santa Catarina
}

\begin{abstract}
Resumo: Este artigo mostra como alguns temas que Merleau-Ponty e Lacan mantêm em comum são tratados poeticamente na Ode Triunfal de Álvaro de Campos (Fernando Pessoa). Trata-se de uma tentativa de exemplificar como a literatura pode expressar a seu modo várias ideias e posições que a filosofia alcança de forma teórica. Apresentamos brevemente os conceitos de Ser Bruto e de Carne, introduzidos por Merleau-Ponty para evitar os dualismos seculares da filosofia. Além disso, esboçamos como ele, em sua obra tardia, discute o visível e o invisível no interior da mesma estratégia de reabilitação da sensibilidade que já encetara em seus primeiros escritos. Em seguida, mostramos como Lacan apropria-se de tais considerações para ressaltar a existência de uma visão, proveniente das coisas mesmas e prenhe de elementos pulsionais, que antecede o olhar do vidente. Para Lacan, o vidente sujeita-se com prazer sacrificial a tal visão e nela aniquila. Por fim, comentamos partes do poema de Pessoa em que se exemplificam os principais pontos em apreço.
\end{abstract}

Palavras-chave: Merleau-Ponty. Lacan. Fernando Pessoa. Carne. Pulsão escópica.

Hoje se diz que tudo se espia, que nada passa despercebido e que mesmo o papel das paredes tem melhor memória que os homens. E não é o bom Deus que tudo vê. Não, um banco de cozinha, um cabide, cinzeiros pela metade ou a escultura de madeira de uma mulher chamada Niobe bastam para proporcionar testemunho imperecivel de cada um de nossos atos ${ }^{1}$.

O tambor, Günter Grass

\section{Introdução}

As interpretações das relações existentes entre o pensamento de Merleau-Ponty e o de Lacan já têm alguma história, fato esse que, por várias razões, não nos deve surpreender de todo. Além de pertencerem à mesma cena cultural francesa, tais autores desenvolveram

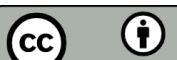

\footnotetext{
* Possui graduação (2008) e mestrado (2011) em Filosofia pela Universidade Federal de Santa Catarina (UFSC). Foi bolsista Santander na Universidade Católica Portuguesa (Braga) (2007) e professor substituto das disciplinas de Ética/Disciplina Consciente e Comunicação/Expressão, na Universidade Federal de Santa Catarina, campus Joinville (2011). Realizou estágio de pesquisa (2014-2015) no departamento de Filologia Clássica da Philipps Universität de Marburgo (Alemanha), sob supervisão do professor Dr. Arbogast Schmitt. Integra desde 2013 a equipe editorial da "Peri - Revista de Filosofia". É membro do NIM - Núcleo de Investigações Metafísicas da UFSC e do Núcleo de Filosofia Antiga da UFSC. Atualmente é aluno de doutorado da UFSC. E-mail: maiconengler@bol.com.br

${ }^{1}$ GRASS, 2006, p. 225.
} 
preocupações teóricas similares: desde o início de sua carreira discutiu Merleau-Ponty com a Psicanálise e com a psicologia de modo geral ${ }^{2}$, e Lacan, como se sabe, aproveitou-se das reflexões de seu amigo e de outros filósofos para elucidar as questões de seu trabalho como psicanalista e pensador polêmico. Em torno de ambos também pairava a mesma névoa ideológica feita de fenomenologia, de marxismo, de psicanálise, de existencialismo etc., a qual, na ausência de vínculos mais explícitos, por si só bastaria para que se rastreasse um traço comum em muitas de suas investigações. O presente artigo enfatiza algumas interseções já notadas por outros estudiosos entre o pensamento desses autores - principalmente no que concerne à problemática da visibilidade e da pulsão escópica - e a maneira como se deixam mostrar em um dos poemas de Fernando Pessoa. Para tanto, expomos dois conceitos de Merleau-Ponty - Ser Bruto e Carne - bem como algumas de suas conclusões acerca da visibilidade e do fato de sermos seres a um só tempo videntes e visíveis. Feito isso, mostramos como Lacan apropria-se dessas reflexões e as retraduz para o contexto psicanalítico, dando especial atenção à pulsão escópica e ao sacrifício subjetivo nela contido, sacrifício esse que, tal como a descida do artista à radicalidade do Ser Bruto, é capaz de franquear um campo psíquico anterior às relações fantasmáticas e imagéticas do Eu. Como esses temas parecem ser evocados na Ode Triunfal de Fernando Pessoa (Álvaro de Campos), citamos e comentamos seus versos mais representativos.

\section{Merleau-Ponty: o ser bruto, a carne, o visível e o invisível}

Tanto na obra $O$ olho e o espírito, quanto nos fragmentos do livro inacabado, $O$ visível e o invisível, nota-se claramente o esforço de Merleau-Ponty para escapar de dois extremos igualmente perigosos e tradicionais: por um lado, o pensamento ativista da ciência, que sobrevoa os fenômenos do mundo e retalha suas singularidades para transformá-lo em "objeto em geral"; por outro, a ânsia subjetivista da filosofia, a qual, encontrando certezas apenas nas operações do $\mathrm{Eu}$, como que engole o mundo inteiro para fazer dele mera soma de representações para um sujeito (MERLEAU-PONTY, 1980a, p. 85). Com um projeto que remonta às suas obras inicias, nas quais também buscava manter-se entre o objetivismo da ciência e o intelectualismo da filosofia, Merleau-Ponty segue certas tendências filosóficas do século XX e procura um âmbito mais original em que esses dualismos da tradição ainda não se tenham solidificado, um lugar em que o sujeito e o objeto, a coisa e a consciência ainda se

\footnotetext{
${ }^{2}$ Vide: MÜLlER-GRANZOTTO, 2005. Entre outras coisas, o artigo mapeia as posições de Merleau-Ponty em relação à Psicanálise, principalmente no que tange aos conceitos de inconsciente e de experiência clínica; mostra a influência que o pensador francês sofreu da leitura de Freud feita por Politzer; e elucida a maneira como tentou elaborar uma psicanálise ontológica, bem como o sentido de conceitos importantes como "expressão" e Gestalt.
} 
apresentem entrelaçados primitivamente e possam ser pensados em sua propriedade, mesmo quando se apresentam de modo confuso (MERLEAU-PONTY, 2000, p. 127). É através da reabilitação da dignidade ontológica do sensível, possibilitada entre outras coisas pela meditação sobre a arte e sobre a experiência da percepção, que ele busca atingir esse "há" primordial - chamado por ele de "Ser Bruto" - que tanto a ciência quanto a filosofia pressupõem em suas investigações.

O Ser Bruto é propriamente o ser da indivisão e do enlace, que ainda não foi submetido às operações fracionantes do cogitare, responsáveis por calcificá-lo nos conceitos da tradição filosófica. Embora alguns filósofos tenham dado atenção casual para isso, pois o mundo da cultura nada mais é do que um parto interminável do Ser Bruto (CHAUÍ, 2002, p. 156), são os artistas que possuem o privilégio de perambular em seu horizonte matricial de sentido. Cada uma das artes tem maneira especial de acolchoar-se nesse lençol originário para extrair daí a seiva que a anima: a pintura utiliza-se principalmente do movimento do corpo e dos olhos, celebrando assim o "mistério da visibilidade", ao passo que a literatura se entremeia nos arcanos do dizível e a música, por sua vez, permanece bastante aquém do designável, exprimindo apenas irrupções, fluxos e refluxos do Ser (MERLEAU-PONTY, 1980a, p. 86). Mais do que arrogar-se o título de nova substância, de um sucedâneo para todos os absolutos fundamentais em que a filosofia se apoiou ao longo da história, o Ser Bruto representa antes a vontade de pensar um estofo comum entre nosso corpo e o mundo, isto é, algo que conceda a Merleau-Ponty a importante afirmação de que "somos o mundo que se pensa" (MERLEAU-PONTY, 2000, p. 132). O visivel e o invisível insiste precisamente na elucidação do pacto já estabelecido entre nosso corpo e o mundo, pacto esse que é anterior a qualquer relação de consciência - "pré-tético", para dizê-lo em termos fenomenológicos - e que revela como penetramos nas coisas através da visão e como elas penetram em nós ao serem vistas (MANZI, 2009, p. 3-4). Esse estofo comum resume-se no conceito de Carne, que é entendida como meio formador do objeto e do sujeito, como elemento ou emblema concreto de uma maneira de ser (MERLEAU-PONTY, 2000, p. 142-3).

Merleau-Ponty ressalta que tal conceito ainda não possui nome em nenhuma filosofia, e o modo reticente como o descreve, premido pelo cuidado de não cair novamente na dependência de um absoluto, lembra alguns aspectos do discurso da teologia negativa, que define seu "objeto" muito mais por negação do que por caracterização positiva. Se algo com que compará-la fosse buscado na história, a Carne então apareceria como um dos antigos elementos (stoicheîa) de que falavam os pré-socráticos, uma coisa geral que, incorporando um 
estilo do Ser, ficasse a meio caminho entre o indivíduo espaço-temporal e a ideia (MERLEAU-PONTY, 2000, p. 136). Parece não ser à toa que Merleau-Ponty faz essa referência aos "elementos" dos pré-socráticos: sempre que a filosofia quer retornar à sua essência, fugindo das soluções prontas da tradição, ela se volta para o que os pré-socráticos pensaram, algo que pode ser visto na obra de Nietzsche e de Heidegger, ambos os quais também lutaram contra a metafísica da representação ${ }^{3}$. Mas nem de longe pode a Carne ser confundida com a matéria, com o espírito ou com uma substância. A despeito de compor-se de idealidade rigorosa - idealidade que realiza, de forma não conceitual, a união e a aderência dos movimentos de uma sonata, ou dos estilhaços do campo luminoso (MERLEAU-PONTY, 2000, p. 146-7) - ela não é presença plena nem sustentáculo do mundo. Ao contrário, a Carne comporta-se como as deiscências dos vegetais, e pode tanto suscitar uma presença, quanto se fazer ausência que anseia por preenchimento. Em verdade, ao mesmo tempo em que promove o visível e o doa à nossa visão como uma figura, ela oculta em profundidade o invisível, realizando como que um movimento de ida e vinda, de emergência e imergência que define o quiasma ou o entrecruzamento desses polos (CHAUÍ, 2002, p. 155). Esta invisibilidade no próprio seio do visível será entendida por Lacan como o objeto pequeno "a", um campo de experiência subjetiva que permanece aquém das imagens (MANZI, 2009, p. 8). Certas obras de arte, como os quadros de Cézanne ou o poema de Pessoa, exploram justamente esse âmbito originário onde se esvaecem as representações sociais e fantasmáticas daquilo que, em Lacan, constitui o Imaginário.

De mais a mais, a noção de Carne enseja nova maneira de conceber o corpo: uma vez que ela seja a polpa comum ao mundo e a nós, já não podem subsistir as divisões estanques entre o lugar que habitamos e aquilo de que somos feitos (MERLEAU-PONTY, 2000, p. 134). O nosso corpo une-se então às coisas por sua própria ontogênese, prendendo-se no tecido delas e pensando-as por contato e inerência. A distância efetiva entre ele e elas - a distância geométrica e cartesiana que punha os objetos em rede de relações -, desaparece e o espaço passa a ser contado a partir de cada corpo senciente, que se torna o ponto zero da espacialidade (MERLEAU-PONTYa, 1980, p. 100). Por ser sensível exemplar, conjunto de

\footnotetext{
${ }^{3}$ Sobre a metafísica da representação: "Merleau-Ponty's theory of the flesh takes up the critique of metaphysics as a representational, and therefore ideological, procedure, a critique that was initiated by Heidegger (through Nietzsche). The support of this anti-representational theory of existence rests upon the analysis of the horizon: the flesh, as a horizontal concept, remains a polymorphous, open system which bears the difference between brute vision and objective thought, both of which are divergent expressions of Being. Thus while for traditional philosophy, Being is the ground of metaphysical identity, the flesh is the ground for existential difference; within the metaphysical tradition difference is derived from identity, while within the theory of the flesh identity is derived from difference, the originary difference of the perceptual Gestalt". Weiss, 1981, p. 82.
} 
cores e superfícies habitado por uma visão e um tato, o corpo pode sentir tudo o que está fora de si, literalmente incorporando a massa sensível para a qual está aberto e tornando-se ser de duas faces: por um lado, coisa entre coisas, por outro, aquilo que as vê e toca (MERLEAUPONTY, 2000, p. 132-3). São essas reflexões, auferidas graças ao conceito de Carne e à reabilitação sensível do corpo, que são retomadas por Lacan, notadamente quando transpostas para a problemática do visível e do invisível. Isso porque, concebendo o corpo ao mesmo tempo como vidente e como coisa visível, feito do mesmo componente pastoso do mundo, Merleau-Ponty descobre a existência de um olhar que emana das coisas e incide sobre o vidente humano. Segundo explica, isto ocorre porque estamos instalados em meio ao visível quando olhamos para as coisas, sem que jamais percamos a possibilidade de sermos vistos, tampouco a visão parcial que temos de nós mesmos. Pela primeira razão, somos possuídos pelo visível que se espraia em nossa circunvizinhança (MERLEAU-PONTY, 2000, p. 131); pela segunda, pois, expressa-se o "narcisismo fundamental de toda a visão", que mais uma vez nos leva a ser tragados pelo visível e a ter de suportar a visão que eflui das coisas.

De sorte que o vidente, estando preso no que vê, continua a ver-se a si mesmo: há um narcisismo fundamental de toda visão; daí por que também ele sofre, por parte das coisas, a visão por ele exercida sobre elas; daí, como disseram muitos pintores, o sentir-me olhado pelas coisas; daí, minha atividade ser identicamente passividade [...] (MERLEAU-PONTY, 2000, p. 131).

Deste modo, quando se utiliza a unidade entre corpo e mundo, a Carne, para pensar o visível, são retirados da visibilidade todos os contornos costumeiros que a faziam apanágio próprio dos seres vivos. Torna-se claro que ora por seu excesso, ora pela ausência que solicita preenchimento, acontecem vários movimentos de reversibilidade em que se entrecruzam o visível e o invisível: são fundos que se tornam figuras e figuras que se tornam fundos, dependendo de como o vidente desloca seu corpo nas entranhas do mundo (CHAUÍ, 2002, p. 166). Nesse jogo entre profundidades e superfícies, não pode haver visão capaz de abarcar a tudo, motivo por que parece que o visível só se doa graças a certa invisibilidade com que se relaciona de modo fundamental e constitutivo, não meramente casual ${ }^{4}$. O conceito de Carne,

\footnotetext{
${ }^{4}$ Apesar de termos falado em superfícies e profundidade, deve-se notar que tal invisibilidade não é apenas mais um visível que se oculta por trás de outra figura que temos diante dos olhos. Ao contrário, a própria visibilidade está impregnada de invisibilidade, uma alteridade radical que impede a total coincidência do vidente com o mundo, haja vista lhe seja impossível ver-se completamente enquanto vê outras coisas. Segundo MüllerGranzotto, a invisibilidade de que fala Merleau-Ponty pode ser vista como possível equivalente do conceito lacaniano de "estranheza" (Unheimlichkeit), que também revela a falta na constituição do sujeito. Para ele, a leitura que Jacques Alain-Miller faz de Merleau-Ponty peca justamente neste ponto: ao pensar que a Carne estabeleceria comunidade perfeita entre o eu e o mundo, no interior da qual estaria eliminada a possibilidade do “estranho”. (MÜLLER-GRANZOTTO, 2008, p. 9-11).
}

Anu. Lit., Florianópolis, v. 20, n. 2, p. 98-115, 2015. ISSNe 2175-7917 
com efeito, elimina as noções usuais de atividade e passividade. É neste ponto preciso que Lacan encontra inspiração no esforço de Merleau-Ponty.

\section{Lacan: o gozo de ser visto e de sujeitar-se à visão}

Lacan admite que Merleau-Ponty esteja fazendo algo novo na filosofia, como que buscando uma substância inominada da qual nós mesmos, os videntes, nos extraímos (LACAN, 1998, p. 81). De acordo com os comentadores, não acredita que Merleau-Ponty tenha caído no antigo sonho dos filósofos e se deixado encantar por presença onividente e similar a Deus (SHEPHERDSON, 2006, p. 119). Podemos dizer que são dois os resultados que ele colhe dessa empresa exploratória e aventureira: a constatação da pré-existência de um olhar, advindo das coisas, que nos fotografa como se fôssemos uma imagem num quadro; e a possibilidade de enquadrar a pulsão escópica, em virtude da esquize entre olhar e visão, no rol das pulsões. Esses dois achados se baseiam, por sua vez, na concepção tipicamente lacaniana do sujeito enquanto falta ou negatividade, que vem agora se apresentar na orla da visão. As reflexões sobre o olhar, assim, antes de remeterem para uma substância primordial em que nos absorvemos, lançam novas luzes sobre o sujeito e permitem compreendê-lo de maneira inovadora (SHEPHERDSON, 2006, p. 120).

Partindo da ideia de que olhamos apenas a partir de um ponto e somos olhados a partir de todos, Lacan conclui, junto com Merleau-Ponty, que somos espelhos do mundo. Seu acréscimo a tal reflexão consiste em perguntar se não existiria alguma satisfação por estarmos sob a perspectiva desse olhar e, ademais, em dizer que o olhar pode conter em si o objeto pequeno 'a', isto é, o objeto paradoxal que localiza uma falta (LACAN, 1998, p. 76-77). A pré-existência do olhar acontece porque as coisas, tendo que ver conosco, ou sendo a mesma Carne, devolvem-nos o olhar que lançamos sobre elas. Lacan relata esse fenômeno com a lembrança de uma pescaria da qual participou. De acordo com seu relato, do barco em que estavam pescando foi avistada uma lata de sardinha a flutuar sobre as águas. O ponto luminoso que a lata criava no meio da água parecia dirigir-se precisamente a eles. Um dos camponeses presentes na pescaria, fazendo uma pilhéria, disse a Lacan que a lata olhava especificamente para ele, singelo pronunciamento que levou o psicanalista a sentir como estava deslocado naquele ambiente: ele, jovem intelectual citadino, pescando por diversão junto de trabalhadores que labutavam pela sobrevivência. Ele concluiu que representava uma mancha no quadro em que se inseria, o que se presta para elucidar como, se olhamos para um quadro ou para um objeto qualquer, como a lata de sardinha, é porque estamos inseridos nele 
de algum modo e, por isso, recebemos sobre nós certa visão (LACAN, 1998, p. 94) ${ }^{5}$. A unidade carnal do vidente e dos visíveis faz que com a visão que emana do primeiro, assim que incide sobre os segundos, seja como que refletida e retorne sobre ele, dando-lhe a sensação de estar sendo espiado no drama do mundo.

Isso se dá, outrossim, pelo fato de ser através do olhar que penetramos na clareira da luz: através dele nos tornamos videntes, ao mesmo tempo em que, entranhados na luminosidade, somos também visíveis (LACAN, 1998, p. 104). Do ponto de vista da luz, sermos vistos é a condição para que vejamos. Lacan insiste que o olhar está sempre do lado de fora no campo da pulsão escópica e voltado para aquilo que nos rodeia; ele é sempre etimologicamente extático ${ }^{6}$. Nesse sentido, no caso específico da pintura, ocorre que às vezes podemos até sentir o olhar das coisas que o pintor selecionou em sua tela, olhar esse que ainda ronda o quadro e nos perscruta. Ele parece pairar, à feição de um nimbo, sobre a plasticidade dos quadros e imagens: os ícones, por exemplo, costumam dar a sensação de sermos vistos pelos entes religiosos ali representados, e na cultura popular muitas pessoas costumam virar as estátuas de seus santos para a parede, quando fazem algo que supostamente não devia ser visto por eles. Aliás, o efeito apolíneo e apaziguante da arte, já constatado por Freud e antes dele por Schopenhauer e Nietzsche, acontece basicamente porque o pintor oferece como que a pastagem que sacia a fome do olho, i.e., faz com que momentaneamente deponhamos nosso olhar sempre ávido - e ávido apenas de olhar por olhar - sobre algo que comporta abandono, uma paisagem ou cena em que o drama do desejo parece ter-se resolvido. (LACAN, 1998, p. 99). Para Lacan, a sublimação consiste na forma como o pintor reduz o objeto 'a', que caracteriza a falta constituinte do desejo do sujeito, em algo que pode ser apreciado artisticamente. Com isso, a negatividade do desejo não é positivada, mas sublima-se e ganha novas vestes, de tal modo que até podemos considerá-la bela, libertando-nos por instantes de

\footnotetext{
${ }^{5}$ Vivências como essas são comuns na literatura, como exemplifica a epígrafe deste artigo. Há em Proust uma descrição de como os objetos do ambiente olhavam para ele, na primeira noite que passou em seu hotel em Balbec. "É a nossa atenção que coloca objetos num quarto, e o hábito quem os retira, abrindo espaço para nós. Espaço era o que não havia para mim em meu quarto de Balbec (meu de nome, apenas); estava cheio de coisas que não me conheciam, que devolveram o olhar desconfiado que lhes lancei e que, sem levar na mínima conta a minha existência, manifestaram que eu desarranjava o ramerrão da sua". (PROUST, 1973, p. 190). Proust continua comentando como uma pêndula fazia considerações pouco lisonjeiras sobre ele em uma língua desconhecida, considerações que as cortinas roxas escutavam sem responder, "mas na atitude análoga à das pessoas que erguem os ombros para mostrar que as irrita a vista de um terceiro". Ele é atormentando pelo olhar e pela presença de cada um dos objetos, mas principalmente por um espelho que não the daria paz enquanto não fosse retirado. Toda a sua agonia só tem fim quando sua avó chega e restabelece a normalidade. PROUST, 1973, p. 190-191.

${ }^{6}$ Esta ideia do olhar como algo extático, sempre voltado para fora, está presente também em Freud e Sartre, sendo constitutiva da tradição filosófica, como os comentários acerca do binômio curiosidade/contemplação o demonstram. Segundo Kelly Oliver, tal ideia se baseia numa visão igualmente alienante de espaço, que ela tenta corrigir através das análises que Luce Irigaray faz sobre a luz e o ar. Cf. OLIVER, 2001.
}

Anu. Lit., Florianópolis, v. 20, n. 2, p. 98-115, 2015. ISSNe 2175-7917 
seu aguilhão. Daí que vem a função civilizadora e encantadora da pintura, a razão pela qual sempre há sociedades dispostas a financiar o trabalho dos pintores (LACAN, 1998, p. 108-9).

Essa avidez que se concentra no olho nada mais é do que a força constante e insopitável de que se compõem as pulsões. O olhar, como órgão da pulsão escópica, é impulso irreprimível que não busca um objeto específico para se apaziguar, mas como que se satisfaz com o simples exercício de sua potência ${ }^{7}$. Para toda a pulsão, o objeto que lhe pode ser oferecido - o seio, no caso da pulsão oral, ou o quadro na pulsão escópica - é indiferente; o prazer apaziguante advém antes da atividade do que do próprio objeto (LACAN, 1998, p. 157-159). Por conseguinte, quando o objeto pequeno "a", em que o sujeito vem fracassar, se faz presente no olhar, ele atua como desejo, isto é, como função estruturante de uma falta (LACAN, 1998, p. 33). É por ter em si tal falta que o olhar que alguém nos dirige é capaz de desconcertar nosso campo de percepção, relembrando a chaga da falta que também carregamos conosco. Nessas ocasiões, vemos nosso semelhante a sustentar opticamente a função do desejo; recebemos dele um olhar que é o avesso da consciência, porque diretamente ligado ao Real; e somos então remetidos para nossa própria negatividade. O campo simbólico de nossa percepção consciente se desconcerta e desfigura, porque sentimos mais uma vez que, assim como ocorre com aquele indivíduo que nos olha e, a rigor, devolve nosso olhar, nossa negatividade não pode ser preenchida, mas é como a roda de Íxion ou o tonel das Danaides, para usar de uma conhecida metáfora de Schopenhauer (LACAN, 1998, p. 88). Além disso, o olho também funciona como objeto pequeno "a" pela relação de logro que sempre ocorre na visão, ou seja, por ela nunca nos ceder o que buscamos, de tal sorte que sempre somos obrigados a recomeçar a busca. Esta é a fenda ou esquize entre o olhar e a visão.

De maneira geral, a relação do olhar com o que queremos ver é uma relação de logro. O sujeito se apresenta como o que ele não é e o que se dá para ver não é o que ele quer ver. É por isso que o olho pode funcionar como objeto $a$, quer dizer, no nível da falta (- $\alpha)$ (LACAN, 1998, p. 102).

Por compreender em si a falta característica do desejo, o olhar enquanto pulsão escópica pertence por excelência ao Real. Diferentemente do Imaginário e do Simbólico, o Real é o maior cúmplice das pulsões e - como a análise clínica o revela - tende a apresentarse em sua incidência dialética de modo originalmente mal-vindo (LACAN, 1998, p. 70). O Imaginário se relaciona com a formação de nossa personalidade através do confronto com

\footnotetext{
${ }^{7}$ Essa descrição do olhar relembra as clássicas análises da curiositas, a ânsia (cura) de simplesmente olhar para as coisas sem nenhum propósito definido, que se difere da contemplação filosófica. Em geral, os filósofos criticaram esse sentimento desde a Antiguidade até o século XX, e à guisa de exemplo podemos citar Platão, com quem isso começa, Agostinho, Pascal e Heidegger. Cf. ENGLER, 2011, pg. 44, nota 117; pg. 227 , nota 476.
} 
imagens que recebemos de nossos semelhantes e também através de sua assimilação: é o estádio mimético que compartilhamos com os animais. O Simbólico, por sua vez, refere-se à estruturação linguística que organiza a experiência: é um sistema de leis com as quais estabelecemos a verdadeira relação que nos constitui como sujeitos. E o Real, pois, é o domínio que, isento de imagens e de particularizações do Inconsciente (fantasmas), só se franqueia a partir do gozo (SAFATLE, 2007, p. 75), razão por que Lacan fazia aquela pergunta, citada acima, sobre o prazer de sermos espelhos do mundo. Há, portanto, satisfação em estarmos sujeitados a um olhar que não é o nosso, nem o de nosso semelhante enquanto sujeito consciente. A relação desse prazer com o tema das pulsões retira do olhar pré-existente todas as conotações que o poderiam caracterizar como propriedade de um sujeito: ele se torna um olhar que vem do Outro (SHEPHERDSON, 2006, p. 115).

Depois de constatar que somos olhados pelas coisas e que isso nos causa satisfação, Lacan ata o fio de suas reflexões graças ao conceito de pulsão. Como toda a pulsão é para ele pulsão de morte, a atividade em que nos sujeitamos ao olhar pré-existente, aquele que desvenda o horizonte da própria visibilidade, tem algo de sacrificial e comporta resquícios mortíferos.

\footnotetext{
Para Lacan, é uma questão de distinção entre o prazer da pulsão, aquele prazer no qual o sujeito desaparece (que Lacan chama de jouissance) e, por contraste, a ordem do desejo na qual o sujeito encontra sua vida. De acordo com Lacan, esta é a antítese que Merleau-Ponty descobre, sem perseguir isto na direção que Freud nos exige tomar: a experiência de estar sob o olhar e, mais precisamente, a satisfação que acompanha isso, essa é a precisamente a experiência da pulsão escópica, esta experiência primordial que é sempre uma possibilidade do sujeito, mas na qual o desejo é perdido e o sujeito se move para sua própria aniquilação (SHEPHERDSON, 2006, p. 124).
}

Provoca-nos estranha satisfação o olhar que nos atravessa por todos os lados e que faz sentir nossa absoluta passividade diante de alguma coisa que nos precede. Este gozo não advém do fato de termos encontrado um significante absoluto que faria cessar a incompletude do desejo, mas sim do fato de que, enquanto sujeito, modificamos o valor do objeto desejado, já que nós mesmos nos aniquilamos. O desaparecimento do sujeito é a marca da pulsão de morte, e tal marca se apresenta agora no olhar para caracterizar a pulsão escópica.

\section{Ode triunfal: o esfacelamento do poeta na totalidade carnal}

O fato de ser possível definir algumas obras de Pessoa como sensacionistas consoante o famoso mote: "sentir tudo de todas as maneiras" -, principalmente as escritas sob o heterônimo Álvaro de Campos, já seria suficiente para que se justificasse sua escolha como 
exemplo artístico dos temas em questão. Contudo, sua riqueza poética é bastante vigorosa para que vários outros poemas pudessem ser selecionados com iguais oportunidades de exemplificar as reflexões de Merleau-Ponty sobre as sensações, respectivamente, e as de Lacan sobre a pulsão escópica. A Ode Triunfal ${ }^{8}$, todavia, permite que as considerações acima se ilustrem principalmente em torno de dois assuntos tratados: a unidade entre corpo e mundo, abarcada pelo conceito de Carne, e a maneira pulsional de relacionar-se com as coisas que têm que ver conosco, com menção explícita do olhar. Outros pontos discutidos também se fazem presente nesse poema: a descida do poeta até o Ser Bruto, donde arranca significações primordiais para o que quer exprimir e onde se alija das representações sociais; o rompimento com a maneira habitual de usarmos os sentidos; a fragmentação na totalidade diante da qual o poeta ora se sente passivo, ora em plena atividade.

O modo como Pessoa locomove-se nas entranhas da totalidade, com efeito, se faz de sucessivos esfacelamentos. Ele reconhece o parentesco original entre as máquinas que vai descrevendo e seu próprio ser, e o espasmo dos maquinismos que percebe atinge-lhe todos os sentidos e faz dele sua extensão contemporânea. Desde o início ele se encontra em um estado inabitual - tem febre e range os dentes ao escrever - e ao longo do poema isso se intensifica até que ele se perca enquanto sujeito em meio à extensão carnal das coisas. Tal como a inspiração poética, os estados de transe e as doenças visionárias, sua febre deve ser vista como indício de uma percepção alterada e diferente da comum, mais afeita à radicalidade do Ser Bruto, do mesmo modo como podemos imaginar que a epilepsia (o morbus sacer dos Antigos) devia proporcionar a Machado de Assis ou a Dostoievski uma percepção diversa das coisas ${ }^{9}$. Nunca é demais recordar, aliás, que a circunstância de composição da Ode Triunfal é também doentia e insólita: ela foi escrita no dia igualmente triunfal (oito de Março de 1914) em que se manifestaram os principais heterônimos de Pessoa, dia em que ele escreveu trinta e tantos poemas de Caeiro (O guardador de rebanhos), o poema Chuva Oblíqua (Fernando Pessoa) e a ode aqui estudada, a qual foi jorrada na máquina de escrever, "sem interrupção nem emenda".

\footnotetext{
${ }^{8}$ PESSOA, Fernando. Obra Poética IV - Poemas de Álvaro de Campos. Porto Alegre, L\&PM, 2007. O poema esta compreendido entre as páginas 44-53; por ser difícil fazê-las acompanhar os versos, não tornaremos a citálas.

${ }^{9}$ A ligação da doença com a arte é atestada desde a Antiguidade, como no Problema XXX de Aristóteles. Merleau-Ponty também a menciona quando comenta a obra de Cézanne. Ele ressalta a vontade explícita do pintor de não ceder à convivência, o que incluía afastar as mulheres de seu atelier, ignorar as teorias rebuscadas de Émile Bernard, evitar Paris ou fazer sinais para que seus amigos não o abordassem, quando acaso o viam pela rua. Merleau-Ponty não acredita que a obra de Cézanne seja um fenômeno da decadência de sua psique, mas admite que "por ocasião dos distúrbios nervosos, Cézanne tenha concebido uma forma de arte válida para todos" (MERLEAU-PONTY, 1980b, p. 114).
} 
À dolorosa luz das grandes lâmpadas elétrica da fábrica, Tenho febre e escrevo.

Escrevo rangendo os dentes, fera para a beleza disto, Para a beleza disto totalmente desconhecida dos antigos.

Ó rodas, ó engrenagens, r-r-r-r-r-r eterno!

Forte espasmo retido dos maquinismos em fúria!

Em fúria fora e dentro de mim,

Por todos os meus nervos dissecados fora,

Por todas as papilas fora de tudo com que eu sinto!

Tenho os lábios secos, ó grandes ruídos modernos,

De vos ouvir demasiadamente de perto,

E arde-me a cabeça de vos querer cantar com um excesso

De expressão de todas as minhas sensações,

Com um excesso contemporâneo de vós, ó máquinas!

As máquinas agem de maneira furiosa dentro e fora do poeta, sem que haja barreira nítida entre esses polos. É o conjunto de suas sensações que está em jogo e todas as características da vida moderna que ele canta - os cafés, as capitais, os elétricos, os guindastes, os trabalhadores etc. - são partes dele mesmo. À medida que as torna presentes por meio das palavras, sente seu ser dividido e espalhado por todos os lados; e sua constatação de que o presente contém em si o passado e o futuro, pois, mostra como ele se encontra no torvelinho da totalidade, em posição mais profunda e originária do que aquela que impera no cotidiano sadio. É neste torvelinho que ele é acariciado num frenesi mecânico. Já aqui se manifesta, sem dúvida, seu desejo sacrificial de ser penetrado fisicamente pelo elemento mecânico, absorvendo-o e tornando-se assim passento, mas ao mesmo tempo completo e orgulhosamente triunfante como uma máquina.

Em febre e olhando os motores como a uma Natureza tropical -

Grandes trópicos humanos de ferro e fogo e força -

Canto, e canto o presente, e também o passado e o futuro,

Porque o presente é todo o passado e todo o futuro

E há Platão e Virgílio dentro das máquinas e das luzes elétricas

Só porque houve outrora e foram humanos Virgílio e Platão,

E pedaços do Alexandre Magno do século talvez cinquenta,

Átomos que hão de ir ter febre para o cérebro do Ésquilo do século cem,

Andam por estas correias de transmissão e por estes êmbolos e por estes volantes,

Rugindo, rangendo, ciciando, estrugindo, ferreando,

Fazendo-me um excesso de carícias ao corpo numa só carícia à alma.

Ah, poder exprimir-me todo como um motor se exprime!

Ser completo como uma máquina!

Poder ir na vida triunfante como um automóvel último-modelo!

Poder ao menos penetrar-me fisicamente de tudo isto,

Rasgar-me todo, abrir-me completamente, tornar-me passento

A todos os perfumes de óleos e calores e carvões

Desta flora estupenda, negra, artificial e insaciável!

No lugar em que se encontra, as convenções sociais e os juízos de valor cotidianos desaparecem, de tal maneira que ele pode amar as coisas mais censuráveis do ponto de vista 
moral - amá-las e, mais do que isso, sentir por elas fome e cio. Aí não se faz presente a ordem de relações rasteiras do dia-a-dia - "abaixo de todos os sistemas morais" - mas outra ordem em que ocorre identificação amoral com a realidade e completa, apaixonada aceitação dela.

Ó tramways, funiculares, metropolitanos,

Roçai-vos por mim até ao espasmo!

Hilla! hilla! hilla-hô!

Dai-me gargalhadas em plena cara,

Ó automóveis apinhados de pândegos e de putas,

Ó multidões quotidianas nem alegres nem tristes das ruas,

Rio multicolor anônimo e onde eu me posso banhar como quereria!

Ah, que vidas complexas, que coisas lá pelas casas de tudo isto!

Ah, saber-lhes as vidas a todos, as dificuldades de dinheiro,

As dissensões domésticas, os deboches que não se suspeitam,

Os pensamentos que cada um tem a sós consigo no seu quarto

$\mathrm{E}$ os gestos que faz quando ninguém pode ver!

Não saber tudo isto é ignorar tudo, ó raiva,

Ó raiva que como uma febre e um cio e uma fome

Me põe a magro o rosto e me agita às vezes as mãos

Em crispações absurdas em pleno meio das turbas

Nas ruas cheias de encontrões!

Ah, e a gente ordinária e suja, que parece sempre a mesma,

Que emprega palavrões como palavras usuais,

Cujos filhos roubam às portas das mercearias

E cujas filhas aos oito anos -- e eu acho isto belo e amo-o! -

Masturbam homens de aspecto decente nos vãos de escada.

A gentalha que anda pelos andaimes e que vai para casa

Por vielas quase irreais de estreiteza e podridão.

Maravilhosa gente humana que vive como os cães,

Que está abaixo de todos os sistemas morais,

Para quem nenhuma religião foi feita,

Nenhuma arte criada,

Nenhuma política destinada para eles!

Como eu vos amo a todos, porque sois assim,

Nem imorais de tão baixos que sois, nem bons nem maus,

Inatingíveis por todos os progressos,

Fauna maravilhosa do fundo do mar da vida!

Ele se mescla de tal modo ao elemento moderno, que vem a ser para as coisas mencionadas algo como a força motriz ou a própria razão da existência delas. As coisas como que o convocam e necessitam dele para existir, realizando seu desejo de estar no íntimo de todas elas.

Nem sei que existo para dentro. Giro, rodeio, engenho-me.

Engatam-me em todos os comboios.

Içam-me em todos os cais.

Giro dentro das hélices de todos os navios.

Eia! Eia-hô! Eia!

Eia! Eu sou o calor mecânico e a eletricidade! 
Com isso, da mesma forma como Cézanne buscava a natureza em sua origem (MERLEAU-PONTY, 1980b, p. 116) ${ }^{10}$, Pessoa também alcança um lugar abaixo do mundo da cultura, a despeito de valer-se de palavras e de pôr em seu canto instrumentos, atividades e demais fenômenos indubitavelmente culturais. Ele também está no âmbito do Ser Bruto. Seu futurismo sensacionista, como a pintura de Cézanne (CHAUÍ, 2002, p. 172), faz com que as máquinas se alijem de suas significações vezeiras, condicionadas à utilidade para os seres humanos, e se tornem tão-somente os impulsos arcaicos que as construíram: elas viram necessidades e futilidades, medos e anseios, alegrias e tristezas. A fim de realizar tal operação de origem, o poeta se vale com tal intensidade da comunhão de sua Carne e das coisas que, não raro, sua expressão só encontra guarida em onomatopeias frenéticas, em guinchos e chiados. Ora, a onomatopeia não significa um primitivismo que, tendo alcançado a paciente cristalização da palavra de modo auditivo, não conceitual, tem suas possibilidades de expressão limitadas. Ao contrário, a fidelidade sonora que mantém em relação àquilo que exterioriza é como que a tentativa de ser a própria coisa em forma de som, de maneira parecida aos "rabiscos" e contornos imprecisos que os impressionistas pintavam, na ânsia de agarrar as coisas tal como se lhes despiam. E, assim, muitas vezes ela dá mostras daquele "lençol de sentido bruto" do qual as palavras extraem, como que por sucção semântica, sua própria dizibilidade significativa.

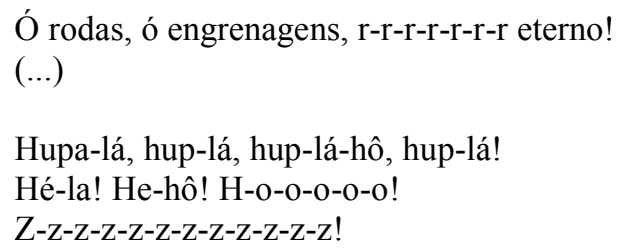

Além da unidade carnal do poeta e das coisas, há que ressaltar os vínculos desiderativos pelos quais ele se relaciona com elas, como já sublinhamos por alto. Aqui se ilustram os temas de Lacan: as coisas têm que ver com o poeta no meio de uma totalidade de sensações libadas por desejos que, às vezes, partem ativamente dele, e às vezes partem delas como excitações sexuais. A menção do amor, do sexo e do cio é recorrente.

Como eu vos amo a todos, a todos, a todos,

Como eu vos amo de todas as maneiras,

Com os olhos e os ouvidos e o olfato,

\footnotetext{
10 “Cézanne aprofunda a síntese, retém aquele movimento circular: o pintor que desejava "criar uma ótica", ver a natureza pela primeira vez, captar nos objetos seus pontos de contato sutis e delicados, também "se atormentava pelo agudo dos matizes"... "Sinto-me colorido de todos os matizes do infinito. Nesse momento, eu e o meu quadro somos um só. Somos um caos irisado. Vou ao encontro do meu motivo, perco-me nele". CAMPOS, 1992, p. 47 (grifos da autora).
} 
E com o tato (o que palpar-vos representa para mim!)

E com a inteligência como uma antena que fazeis vibrar!

Ah, como todos os meus sentidos têm cio de vós!

Depois de inúmeros versos que resumem características da vida moderna, trazendo à tona suas manifestações mais díspares, Álvaro de Campos declara que desejaria ser o souteneur (cáften) disso tudo, dispondo das coisas, portanto, como de uma mercadoria sexual. Sua perambulação em meio a tudo o que é moderno relembra a impossibilidade de satisfação do olhar, a falta característica do sujeito que o leva a contemplar incessantemente os objetos; e parece que o intento da ode não é encontrar alguma coisa, mas perder-se sacrificialmente na babel dos inventos mecânicos. A ligação íntima do poeta com as coisas, de resto, é feita de um paroxismo em que oposições rotineiras, como a existente entre os polos passivo e ativo, se desfazem para dar lugar a um estado de outra ordem. Por um lado, isso justifica a ideia de Merleau-Ponty segundo a qual existe deveras expiração e inspiração do ser, "ação e paixão tão pouco discerníveis, que já não se sabe quem vê e quem é visto" (MERLEAU-PONTY, 1980, p. 92). Pessoa, por estar no cenário cru da indivisão, desconhece as paliçadas que o separam das coisas. Por outro lado, em razão do vocabulário fortemente sexual, isso mostra o conteúdo pulsional que é sublimado pela poesia - o objeto pequeno 'a' que entra em circulação social adornado por vestes métricas e melodiosas.

Fraternidade com todas as dinâmicas!

Promíscua fúria de ser parte-agente

Do rodar férreo e cosmopolita

De comboios estrênuos.

E adiante:

\footnotetext{
Na minha mente turbulenta e incandescida Possuo-vos como a uma mulher bela,

Completamente vos possuo como a uma mulher bela [que não se ama.
}

Este conteúdo sexual, que a princípio se manifesta na relação desiderativa que une o poeta às coisas, aos poucos deixa de lado a intenção saudável e promotora de vida que perfaz o desejo, conectado ao princípio do prazer, para adquirir, através da exacerbação daqueles esfacelamentos já mencionados, a intenção de morte do sujeito, que é característica de todas as pulsões. Em verdade, é difícil de ver no poema alguma intenção promotora de vida, e antes salta muito mais à vista aquele desaparecimento sacrificial do indivíduo de que falamos acima. São mencionados vários aviltamentos que o poeta deseja para si mesmo: partir a cabeça nas esquinas, ensanguentar-se por completo, ser levado por desconhecidos, receber gargalhadas na cara etc. O modo como ele olha para as coisas (eis a pulsão escópica) é duas 
vezes designado como "pervertido": ele se regala com a atividade constante e insopitável de olhar para elas e de enroscar-se em seus contornos, com a atividade de fracassar e não encontrar seu objeto do desejo - "vos possuo como a uma mulher bela que na se ama" -, e anseia por ser tragado por aquilo que mantém em seu campo visual ou, como é indistinguível o lugar donde parte tal impulso, as próprias coisas vistas querem esmigalhá-lo em seu torvelinho. O ponto culminante dessa aniquilação, que inverte a relação de ativa posse sexual citada anteriormente, se dá com a admissão da vontade de morrer entregando-se como se fora uma mulher. Contudo, dado que não seja possível distinguir com exatidão os extremos ativo e passivo, poderíamos dizer que tal desejo é simultaneamente sádico e masoquista.

\author{
Amo-vos a todos, a tudo, como uma fera. \\ Amo-vos carnivoramente, \\ Pervertidamente e enroscando a minha vista \\ Em vós, ó coisas grandes, banais, úteis, inúteis, \\ Ó coisas todas modernas, \\ Ó minhas contemporâneas, forma atual e próxima, \\ Do sistema imediato do Universo! \\ $(\ldots)$ \\ Eu podia morrer triturado por um motor \\ Com o sentimento de deliciosa entrega de uma mulher possuída. \\ Atirem-me para dentro das fornalhas! \\ Metam-me debaixo dos comboios! \\ Espanquem-me a bordo de navios! \\ Masoquismo através de maquinismos! \\ Sadismo de não sei quê moderno e eu e barulho! \\ Up-lá jockey que ganhaste o Derby, \\ Morder entre dentes o teu cap de duas cores! \\ (Ser tão alto que não pudesse entrar por nenhuma porta! \\ Ah, olhar é em mim uma perversão sexual!
}

E no último verso:

"Eia e hurrah por mim-tudo e tudo, máquinas a trabalhar, eia!

Galgar com tudo por cima de tudo!

(..)

A não ser eu toda a gente e toda a parte!

O final do poema realiza, portanto, a consubstanciação carnal dos artefatos modernos com o olhar pulsional do poeta e com seu ser, fazendo com que tudo se integre num mesmo estofo carnal, no âmbito do Ser Bruto e abaixo da cultura estabelecida pela sociedade noutras palavras, abaixo do Imaginário. 


\section{Conclusão}

Através dos conceitos de Ser Bruto e de Carne, entre outros conceitos não elaborados neste artigo, Merleau-Ponty realiza a quebra com os dualismos da tradição filosófica e descobre a existência de um olhar que brota das coisas e fotografa o vidente. Lacan apropriase dessa ideia e acrescenta que a sujeição do vidente a tal olhar é prazerosa e se relaciona com a sublimação. O prazer a que Lacan se refere, porém, é de ordem pulsional e acarreta a aniquilação sacrificial do sujeito que o vivencia. Alguns desses aspectos se exemplificam no poema de Pessoa: ali o poeta se estilhaça com satisfação na totalidade que evoca e que se relaciona com ele por via do desejo ou, mais corretamente, por via da pulsão. A sua relação era pulsional por desembocar na própria morte, incentivada tanto por ele quanto pelas coisas descritas, já que a divisão entre passividade e atividade tornara-se demasiado tênue. Embora todos os sentidos apareçam no poema, é importante notar que o olhar é duas vezes designado como uma perversão sexual. Como dissemos, a maioria dos poemas de cunho sensacionista, escritos sob o heterônimo Álvaro de Campos, expressam tais temas de modo exemplar; Campos sente as coisas de tal modo intenso, que muitas vezes se perde em meio a elas ${ }^{11}$. Pessoa se apraz em descrever uma aniquilação de si mesmo que, semelhante à petite mort do sexo, causa-lhe prazer, ainda que o aproxime mais e mais da morte. E o olhar frequentemente surge em cena como lugar privilegiado em que isso se dá. Citemos, para concluir, um excerto do poema "Passagem das Horas" (PESSOA, 2007, p. 119):

\footnotetext{
Os braços de todos os atletas apertaram-me subitamente feminino, E eu só de pensar nisso desmaiei entre músculos supostos. Foram dados na minha boca os beijos de todos os encontros. Acenaram no meu coração os lenços de todas as despedidas, Todos os chamamentos obscenos de gestos e olhares Batem-me em cheio em todo o corpo com sede nos centros sexuais.
}

É mais um exemplo, em suma, de como a arte pode antever ou resumir aspectos do pensamento filosófico mais abstrato e teórico. Muitas vezes, aquilo que Atena só com muita dificuldade concede aos pensadores, as Musas doam com gratidão aos poetas ${ }^{12}$.

\section{Referências}

CAMPOS, Maria J. R. Arte e Verdade. São Paulo: Loyola, 1992.

CHAUÍ, Marilena. Experiência do Pensamento: ensaios sobre a obra de Merleau-Ponty. São Paulo: Martins Fontes, 2002.

\footnotetext{
${ }^{11}$ Para uma diferença entre os tipos de olhar dos heterônimos e do próprio Pessoa, vide: SILVA, 1995.

12 Gostaríamos de agradecer ao Prof. Marcos Müller-Granzotto por haver chamado nossa atenção para esses temas e, mais do que isso, por haver oferecido os instrumentos necessários para entendê-los.
} 
ENGLER, Maicon Reus. Tò thaumázein: a experiência de maravilhamento e o princípio psíquico da filosofia em Platão. Dissertação (mestrado), Universidade Federal de Santa Catarina, Programa de Pós-Graduação em Filosofia, 2011.

GRASS, Günter. O tambor. Rio de Janeiro: Nova Fronteira, 2006.

LACAN, Jacques. O Seminário, livro XI: Os Quatro Conceitos Fundamentais da Psicanálise. Rio de Janeiro: Jorge Zahar, 1998.

MANZI, Ronaldo F. Um possível anonimato na Visibilidade - um diálogo entre MerleauPonty e Lacan. Revista de Estudos Lacanianos, Belo Horizonte, Ano II, n. 3, janeiro-outubro, 2009, p. 75-82.

MERLEAU-PONTY, Maurice. O Olho e o Espírito. São Paulo: Abril Cultural, 1980a (Os pensadores).

. A Dúvida de Cézanne. São Paulo: Abril Cultural, 1980b (Os pensadores).

. O Visível e o Invisivel. São Paulo: Ed. Perspectiva, 2000.

MÜLLER-GRANZOTTO, Marcos J. Merleau-Ponty e Lacan: a respeito do estranho. Revista AdVerbum, v.III, n. 1, Janeiro-Julho, 2008, p. 3-17.

. Merleau-Ponty leitor de Freud. Revista Natureza Humana, São Paulo, v. 7, n. 2, Julho-Dezembro, 2005, p. 399-432.

OLIVER, Kelly. The Look of Love. Hypatia, v. 16, n. 3, Summer-2001, p. 56-78.

PESSOA, Fernando. Obra Poética IV - Poemas de Álvaro de Campos. Porto Alegre: L\&PM, 2007.

PROUST, M. À sombra das raparigas em flor. Trad. de Mário Quintana. 2.ed. Porto Alegre: Globo, 1973.

SAFATLE, Vladimir. Lacan. São Paulo: Publifolha, 2007.

SHEPHERDSON, Charles. Uma Libra de Carne: a leitura lacaniana d' O Visível e o Invisível. Discurso, Revista do Departamento de Filosofia da USP, n. 36, 2006, p. 97-125.

SILVA, Úrsula Rosa da. O olhar em Pessoa e em Merleau-Ponty. Revista Dissertatio, v. 1, n. 1, Pelotas, Inverno, 1995.

WEISS, Allen S. Merleau-Ponty's concept of the "flesh" as libido theory. Substance, University of Wisconsin Press, v. 10, n. 1, Issue (30), 1981, p. 85-95.

[Recebido em abril de 2015 e aceito para publicação em junho de 2015]

\section{Merleau-Ponty, Lacan and Pessoa: the driving shattering of vision}

Abstract: This article shows how some themes that Merleau-Ponty and Lacan have in common are poetically treated in the poem Ode Triunfal by Álvaro de Campos (Fernando 
Pessoa). It is an attempt to exemplify how literature can express in its own way many ideas and positions that philosophy reach theoretically. I explain the concepts of flesh and wild Being that Merleau-Ponty introduces in order to avoid the century-old dualisms of philosophy. Moreover, I sketch how he discusses, in his late work, the visible and the invisible within the same strategy of rehabilitation of sensibility that he had employed in his first writings. After this, I show how Lacan appropriates such ideas in order to point out the existence of a certain kind of vision, full of driving elements, that comes from the things and precedes the gaze of the viewer. According to Lacan, the viewer submits with sacrificial pleasure to such vision and annihilates himself in it. Finally, I comment on some parts of Pessoa's poem to exemplify these issues.

Keywords: Merleau-Ponty. Lacan. Fernando Pessoa. Scopic drive.

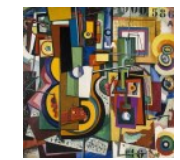

